\title{
Clinical Performance of an Ultrahigh Resolution Chromosomal Microarray Optimized for Neurodevelopmental Disorders
}

\author{
Karen S. Ho, ${ }^{1,2}$ Hope Twede, ${ }^{1}$ Rena Vanzo, ${ }^{1}$ Erin Harward, ${ }^{1}$ Charles H. Hensel, ${ }^{1}$ \\ Megan M. Martin, ${ }^{1}$ Stephanie Page, ${ }^{1}$ Andreas Peiffer, ${ }^{1,2}$ Patricia Mowery-Rushton, ${ }^{1}$ \\ Moises Serrano, ${ }^{1}$ and E. Robert Wassman ${ }^{1}$ \\ ${ }^{1}$ Lineagen, Inc., Salt Lake City, UT, USA \\ ${ }^{2}$ Department of Pediatrics, University of Utah, Salt Lake City, UT, USA
}

Correspondence should be addressed to E. Robert Wassman; bwassman@lineagen.com

Received 17 June 2016; Revised 27 September 2016; Accepted 20 October 2016

Academic Editor: Urzsula Demkow

Copyright (C) 2016 Karen S. Ho et al. This is an open access article distributed under the Creative Commons Attribution License, which permits unrestricted use, distribution, and reproduction in any medium, provided the original work is properly cited.

Copy number variants (CNVs) as detected by chromosomal microarray analysis (CMA) significantly contribute to the etiology of neurodevelopmental disorders, such as developmental delay (DD), intellectual disability (ID), and autism spectrum disorder (ASD). This study summarizes the results of 3.5 years of CMA testing by a CLIA-certified clinical testing laboratory 5487 patients with neurodevelopmental conditions were clinically evaluated for rare copy number variants using a 2.8 -million probe custom CMA optimized for the detection of CNVs associated with neurodevelopmental disorders. We report an overall detection rate of $29.4 \%$ in our neurodevelopmental cohort, which rises to nearly $33 \%$ when cases with DD/ID and/or MCA only are considered. The detection rate for the ASD cohort is also significant, at 25\%. Additionally, we find that detection rate and pathogenic yield of CMA vary significantly depending on the primary indications for testing, the age of the individuals tested, and the specialty of the ordering doctor. We also report a significant difference between the detection rate on the ultrahigh resolution optimized array in comparison to the array from which it originated. This increase in detection can significantly contribute to the efficient and effective medical management of neurodevelopmental conditions in the clinic.

\section{Introduction}

Neurodevelopmental disabilities, including developmental delay (DD), intellectual disability (ID), and autism spectrum disorder (ASD), affect up to 15\% of children [1]. However, in the majority of cases, a child's clinical presentation does not allow for a definitive etiological diagnosis. Copy number variants (CNVs) contribute significantly to the etiology of neurodevelopmental disorders, as well as syndromes of multiple congenital anomalies (MCA). The clinical utility of chromosomal microarray analysis (CMA) for the detection of CNVs associated with these disorders has been recognized by multiple professional societies and has been deemed the first-tier clinical diagnostic test for the evaluation of these disorders [2-6].

Microarrays of various designs and reflective of variable genomic content have been applied to the clinical care of individuals with these conditions; as such, there are varying degrees of diagnostic yield with an increase over time as arrays have evolved [7-17]. The ACMG issued a guideline in 2011 on the optimal design of CMAs and recommended inclusion of additional probe content in areas of known relevance [18]. Most studies reporting on the clinical performance of CMA have been on populations enriched by virtue of the nature of the reporting institution and relative indications for testing.

This study summarizes the results of routine clinical CMA testing in a CLIA-certified laboratory using an array specifically designed to increase detection of CNVs in genomic regions of demonstrated relevance to DD/ID/ASD over a period of 3.5 years.

\section{Materials and Methods}

2.1. Patient Ascertainment. Data were obtained from a consecutive series of routine clinical samples referred for CMA 
to a CLIA-licensed laboratory for etiological diagnosis of DD/ ID/ASD and MCAs between July 2012 and December 2015. Patients selectively ascertained and tested as a part of research studies were excluded from these analyses to preclude bias in the observed rates of diagnosis. A second smaller series of 1194 CMAs performed on the same cohort (i.e., identical referral base and underlying patient demographics) with the Affymetrix CytoScan ${ }^{\circledR}$ HD array run during development and local regulatory approval periods is compared here as well to control for the likely ascertainment bias present in previously published reports. Testing indications used here to group patients are defined by the codes routinely provided by referring physicians when ordering tests and are derived from the International Classification of Diseases, Clinical Modification, Revisions 9 or 10, (ICD-9 and ICD-10) from the Centers for Medicare \& Medicaid Services (https://www.cms .gov/).

2.2. Microarray Design. The custom microarray [FirstStepDX PLUS $^{\circledR}$ (FSDX PLUS ${ }^{\circledR}$ ), Lineagen, Inc.] was utilized in this study in all cases except where specified, and its analytical and clinical validation has been described in detail elsewhere [19]. It is an expanded whole genome chromosomal microarray (CMA) built upon the ultrahigh resolution Affymetrix CytoScan HD platform plus 88,435 custom probes targeting genomic regions strongly associated with ID/DD/ASD [15-24] added under good manufacturing practices (GMP) by Affymetrix using their previously described microarray design process [16]. This resulted in a grand total of 2,784,985 probes. Both copy number (CNV) and single nucleotide polymorphic (SNP) probes are included in the array, which is consistent with the ACMG guideline for CMA design, as is the "enrichment of probes targeting dosage-sensitive genes known to result in phenotypes consistent with common indications for a genomic screen" [18]. Such critical regions that did not contain $\geq 1$ probe/1000 bp on the baseline array were supplemented with additional probe content to provide improved detection of smaller deletions and duplications. Additional probe enrichment targeted genomic regions identified by our prior studies and identified elsewhere in the medical literature. These regions included published copy number variants and individual genes associated with DD/ID/ASD [20-29]. The increase in analytical sensitivity resulting from this additional $3.3 \%$ probe content has been calculated to be $2.6 \%$ [19].

2.3. CMA Performance and Interpretation. CMA was routinely performed on DNA extracted by standard methodologies from buccal swab samples (ORAcollect ${ }^{\circledR}$ ) in a CLIAcertified laboratory. CMA reagents and equipment were as specified by Affymetrix. The established standard cytogenetic criteria for interpretation were routinely applied [30] with minimum of 25-consecutive impacted probes as the baseline determinant for deletions and 50 probes for duplications. Rare CNVs ( $<1 \%$ overall population frequency) were determined to be "pathogenic" if there was sufficient published clinical evidence (at least two independent publications) to indicate that haploinsufficiency or triplosensitivity of the
TABLE 1: Overall diagnostic yield of 5487 chromosomal microarrays in a routine clinical population.

\begin{tabular}{lcccc}
\hline & CMAs & $\begin{array}{c}\text { Pathogenic } \\
\text { (\% yield) }\end{array}$ & $\begin{array}{c}\text { VOUS } \\
\text { (\% yield) }\end{array}$ & $\begin{array}{c}\text { Normal } \\
(\% \text { yield })\end{array}$ \\
\hline Total & 5487 & $506(9.2)$ & $1109(20.2)$ & $3872(70.6)$ \\
Female & 1558 & $217(13.5)$ & $325(20.2)$ & $1065(66.3)$ \\
Male & 3929 & $342(8.6)$ & $797(20.1)$ & $2825(71.3)$ \\
\hline
\end{tabular}

region or gene(s) involved is causative of clinical features. If, however, such clinical evidence was insufficient, but at least some preliminary evidence existed for a causative role for the region or gene(s) therein, and they were not previously categorized as normal population variants in the Database of Genomic Variants (DGV) [31], they were classified as variants of unknown significance (VOUS). Areas of absence of heterozygosity $(\mathrm{AOH})$ were also classified as VOUS if they were of sufficient size and location to increase the risk for conditions with autosomal recessive inheritance or conditions with parent-of-origin/imprinting effects. Cases with no CNVs or only CNVs determined by these criteria to most likely represent normal population variants, for example, contained in databases such as DGV documenting presumptively benign $\mathrm{CNVs}$, were reported as normal.

\section{Results}

3.1. Overall Findings and Diagnostic Yield. A total of 5487 FSDX PLUS CMAs were performed in this time period. There were 1558 females and 3929 males (M:F: $2.5: 1)$ tested with a mean age of 7.2 years (median 5.5 years) (Table 1 ). While largely targeting a pediatric population, a subset of 225 patients was comprised of adults over 18 years old (parental and sibling studies excluded). Based on ICD-9 and ICD-10 codes at the time of referral, 3134 cases represented patients with intellectual (ID) or developmental (DD) disability of varying degrees, 3016 cases represented patients with ASD with or without other features, 743 cases represented patients with multiple congenital anomalies, and 1507 cases represented patients with speech/language delay. Referring physicians were pediatricians (15.0\%), medical geneticists (11.2\%), pediatric neurologists $(40.2 \%)$, developmental pediatricians (31.6\%), psychiatrists $(1.7 \%)$, and other medical practitioners $(0.4 \%)$.

The most common pathogenic findings detected in this unselected population of individuals with neurodevelopmental disorders are shown in Figure 1.

Overall, there were 506 (9.2\%) pathogenic abnormalities and $1109(20.2 \%)$ VOUS observed or a $29.4 \%$ overall CNV diagnostic yield for potentially abnormal findings (Table 1). However, the yield of pathogenic findings varies significantly on a multivariate basis including but not limited to referring physician specialty, age of patient at testing, patient gender, and referring indication or combination of indications. In addition, a single individual with a reported $\mathrm{CNV}$ may have more than one pathogenic $\mathrm{CNV}$, a pathogenic $\mathrm{CNV}$ as well as a VOUS, or multiple VOUS findings in the same patient. Patients with any reportable finding had on average $1.2 \mathrm{CNVs}$ 


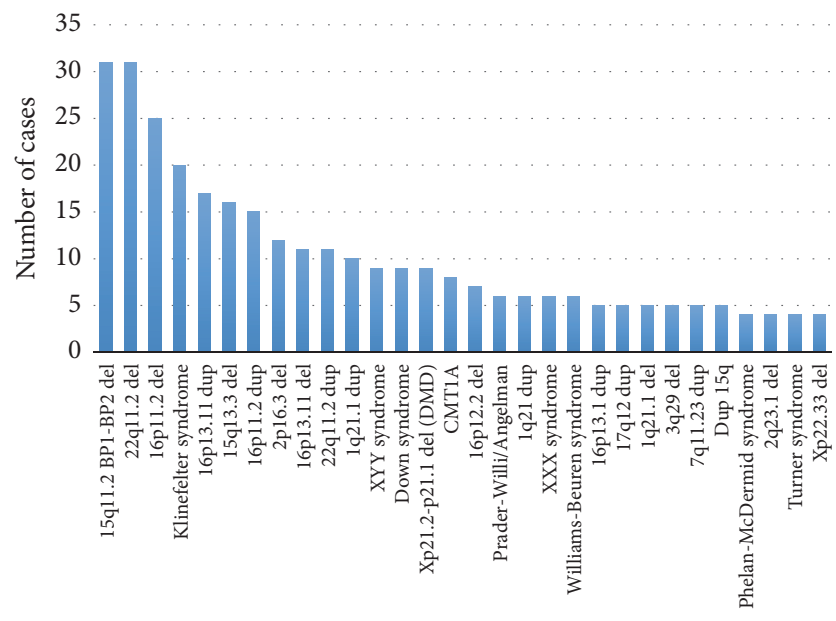

FIGURE 1: Most common pathogenic findings on 5487 chromosomal microarrays (FSDX PLUS).

TABLE 2: Multiple CNV are observed in individual patients (mean 1.2 per patient).

\begin{tabular}{lcc}
\hline & $\begin{array}{c}\text { Total number of individual } \\
\text { CNVs detected }\end{array}$ & $\begin{array}{c}\text { CNVs per 100 tests } \\
(N=5487)\end{array}$ \\
\hline ABN & 734 & 13.4 \\
VOUS & 1272 & 23.2 \\
\hline
\end{tabular}

per report. Of these, there were 13.4 CNVs classified as pathogenic and 23.2 CNVs classified as a VOUS per $100 \mathrm{CMAs}$ (Table 2).

Rates vary significantly by the specialty of the ordering physician (Table 3), but, regardless of specialty expertise, clinically significant rates of detection were observed in all specialties as well as in the primary care setting. At the extremes were psychiatrists (5.5\% diagnostic yield) and medical geneticists (15.5\% diagnostic yield), and these groups also differed significantly in the rate of VOUSs (30\% and $20 \%$, resp.).

Reported duplications are significantly larger than deletions on average (Table 4). For both duplications and deletions, the average size of pathogenic CNVs was significantly larger than CNVs classified as a VOUS $(p<0.0001$, twotailed unpaired $t$-test).

3.2. Detection Rates by Indication and Age. In patients where the indication for testing was either DD/ID or MCA, the rate of pathogenic CNVs was highest in the first year of life at $16.8 \%$ and $21.3 \%$, respectively (Tables 5 and 6 ). Values were lower but consistent throughout the remainder of childhood but peaked again in the small subset of adult patients tested at levels similar to the first year of life (16.8\% and $20.0 \%$, resp.).

Due to the age of clinical recognition, indications including ASD and speech/language deficits were not stratified as to the first year of life separately, but rather with a 0-3.4-year range as the lowest cohort considered. Patients with indications of speech/language deficits demonstrated a gradual rise in the rate of pathogenic findings from the $0-3.4$-yearold group $(6.7 \%)$ to peak in later childhood $(12.8 \%)$, then dropping slightly in adolescence $(10.8 \%)$ and reaching a maximum in the adults tested (19.1\%) (Tables 7 and 8 ). VOUS rates were the highest in the youngest cohort (22.2\%) and relatively constant in the other age groups but distinctly the lowest in the adults (14.9\%).

Individuals with ASD as an indication for testing had a lower pathogenic yield but comparable VOUS rates to other categories (Table 7 ). The pathogenic rate rose gradually from $3.8 \%$ in the youngest cohort ( $0-3.4$ years) to a peak at $8.7 \%$ in adolescence. The overall reported $\mathrm{CNV}$ rate for individuals with ASD ranged within 22\%-29\%, again with the peak in adolescents tested. Those with ASD not only had lower, albeit substantial, pathogenic CNV rates than those with other indications but also clearly lowered the rate for all other indications when it was an additional indication; for example, DD/ID/MCA rate when ASD ICD-9/ICD-10 code was excluded was $13.4 \%$ (Table 9 ). The diagnostic yield excluding ASD is significantly higher $(p<0.0001)$ than for the ASD cohort (13.4\% compared to $5.9 \%$, resp.).

VOUS rates tended to be relatively constant across groups and with age (18-22\%) with the exception of a significantly lower rate in the first year of life for those with DD/ID indication $(15.8 \%)$, which could be due to the small sample size (Table 5), and adults with MCAs or speech/language deficits (14.3\% and $14.9 \%$, resp.) (Tables 6 and 8 ). Those with MCAs also showed higher peak rates of $24.6 \%$ and $25 \%$ in the early childhood (1-3.4 years) and late childhood (5.5-10.1 years) cohorts and a dip, again potentially due to small sample size in this group, to $15.8 \%$ between these ages (Table 6).

3.3. Comparison to Detection on Baseline Array. Detection rates in the same overall cohort (i.e., same referral base, underlying patient demographics timeframe, laboratories, and interpretation process and criteria) on the CytoScan HD array $(N=1194)$, which was the baseline for FSDX PLUS, were lower than those in this series diagnosed on the custom FSDX PLUS array (9.0\% pathogenic CNV and 14.2\% VOUS compared to $9.2 \%$ and $20.2 \%$, resp.) (Table 10 ).

\section{Discussion}

CMA is the guideline-recognized first-tier test in the evaluation of MCA, DD/ID, and ASD, [2-6] and yields significant rates of abnormal or potentially abnormal (VOUS) results [7-17] with clinical utility for the management of individuals with these disorders [28, 29, 32-39]. Since the introduction of this technology, the total genomic content in terms of probes on CMAs has progressively increased, leading to higher diagnostic yields and resolution of abnormalities [10, 14-17] with corresponding increases in clinical value of these tests [3240]. In addition to guidelines on the clinical indications for CMA, ACMG has issued guidance on the appropriate content and design of such arrays and specifically opined that "it is desirable to have enrichment of probes targeting dosagesensitive genes known to result in phenotypes consistent with common indications for a genomic screen (e.g., intellectual disability, developmental delays, autism, and congenital anomalies)" [18]. We report here on over three years' experience 
TABLE 3: Diagnostic yield and mean patient age vary significantly by the specialty of the ordering physician.

\begin{tabular}{|c|c|c|c|c|c|}
\hline Specialty & $\begin{array}{c}\% \text { total CMAs } \\
\text { ordered }\end{array}$ & $\begin{array}{c}\text { Average age } \\
\text { (years) } \\
{[6.4 \text { overall] }}\end{array}$ & $\begin{array}{c}\text { Pathogenic } \\
\% \text { yield }\end{array}$ & $\begin{array}{l}\text { VOUS } \\
\% \text { yield }\end{array}$ & $\begin{array}{c}\text { Normal } \\
\%\end{array}$ \\
\hline Pediatric neurology & $40.2 \%$ & 6.5 & $8.2 \%$ & $20.0 \%$ & $71.8 \%$ \\
\hline $\begin{array}{l}\text { Developmental and } \\
\text { behavioral pediatrics }\end{array}$ & $31.6 \%$ & 6.1 & $7.1 \%$ & $20.6 \%$ & $72.3 \%$ \\
\hline Pediatrics & $15.0 \%$ & 6.8 & $11.2 \%$ & $17.6 \%$ & $71.2 \%$ \\
\hline Genetics & $11.2 \%$ & 6.0 & $15.5 \%$ & $20.1 \%$ & $64.4 \%$ \\
\hline Psychiatry & $1.7 \%$ & 10.7 & $5.5 \%$ & $29.7 \%$ & $64.8 \%$ \\
\hline Other specialties & $0.4 \%$ & 8.3 & $13.6 \%$ & $18.2 \%$ & $68.2 \%$ \\
\hline
\end{tabular}

TABLE 4: Clinically reported duplications are significantly larger than deletions on average.

\begin{tabular}{llcc}
\hline & & Deletions & Duplications \\
\hline Pathogenic & Average size $(\mathrm{kb})$ & 3,284 & 8,105 \\
CNVs & & $(N=474)$ & $(N=258)$ \\
& Median size $(\mathrm{kb})$ & 1,418 & 1,680 \\
\hline \multirow{2}{*}{ VOUS CNVs } & Average size $(\mathrm{kb})$ & 308 & 528 \\
& Median size $(\mathrm{kb})$ & 129 & 357 \\
\hline
\end{tabular}

TABLe 5: Diagnostic yield by age in ID/DD (986 females and 2148 males, total $n=3134$ ).

\begin{tabular}{lcccc}
\hline $\begin{array}{l}\text { Age in } \\
\text { years }\end{array}$ & Total tests & $\begin{array}{c}\text { Pathogenic } \\
(\% \text { yield) }\end{array}$ & $\begin{array}{c}\text { VOUS } \\
(\% \text { yield) }\end{array}$ & Normal (\%) \\
\hline $0-1$ & 95 & $16(16.8 \%)$ & $15(15.8 \%)$ & $64(67.4 \%)$ \\
$1-3.4$ & 950 & $87(9.2 \%)$ & $188(19.8 \%)$ & $675(71.1 \%)$ \\
$3.5-5.4$ & 572 & $54(9.4 \%)$ & $103(18.0 \%)$ & $415(72.6 \%)$ \\
$5.5-10.0$ & 775 & $92(11.9 \%)$ & $152(19.6 \%)$ & $531(68.5 \%)$ \\
$10.1-18$ & 623 & $65(10.4 \%)$ & $117(18.8 \%)$ & $441(70.8 \%)$ \\
$18+$ & 119 & $20(16.8 \%)$ & $26(21.8 \%)$ & $73(61.3 \%)$ \\
Total & 3134 & $334(10.7 \%)$ & $601(19.2 \%)$ & $2199(70.2 \%)$ \\
\hline
\end{tabular}

TABle 6: Diagnostic yield by age in MCA (289 females and 454 males, total $n=743$ ).

\begin{tabular}{lcccc}
\hline Age buckets & Total tests & $\begin{array}{c}\text { Pathogenic } \\
\text { (\% yield) }\end{array}$ & $\begin{array}{c}\text { VOUS } \\
\text { (\% yield) }\end{array}$ & Normal (\%) \\
\hline 0-1 years & 122 & $26(21.3 \%)$ & $23(18.9 \%)$ & $73(59.8 \%)$ \\
1-3.4 years & 179 & $29(16.2 \%)$ & $44(24.6 \%)$ & $106(59.2 \%)$ \\
3.5-5.4 years & 95 & $14(14.7 \%)$ & $15(15.8 \%)$ & $66(69.5 \%)$ \\
5.5-10.4 years & 164 & $30(18.3 \%)$ & $41(25.0 \%)$ & $93(56.7 \%)$ \\
$10.5-18$ & 148 & $28(18.9 \%)$ & $29(19.6 \%)$ & $91(61.5 \%)$ \\
$18+$ & 35 & $7(20.0 \%)$ & $5(14.3 \%)$ & $23(65.7 \%)$ \\
Total & 743 & $134(18.0 \%)$ & $157(21.1 \%)$ & $452(60.8 \%)$ \\
\hline
\end{tabular}

with a unselected clinical referral base on a CMA specifically designed to extend the scope of detection for individuals with ASD and other neurodevelopmental disorders through the addition of probes targeting genomic regions more recently identified as of pathogenic relevance to these disorders.
TABle 7: Diagnostic yield by age in ASD (622 females and 2394 males, total $n=3016$ ).

\begin{tabular}{lcccc}
\hline Age in years & $\begin{array}{c}\text { Number } \\
\text { of tests }\end{array}$ & $\begin{array}{c}\text { Pathogenic } \\
\text { (\% yield) }\end{array}$ & $\begin{array}{c}\text { VOUS } \\
\text { (\% yield) }\end{array}$ & Normal (\%) \\
\hline $0-3.4$ & 735 & $28(3.8 \%)$ & $134(18.2 \%)$ & $573(78.0 \%)$ \\
$3.5-5.4$ & 688 & $33(4.8 \%)$ & $121(17.6 \%)$ & $534(77.6 \%)$ \\
$5.5-10$ & 789 & $50(6.3 \%)$ & $158(20.0 \%)$ & $581(73.6 \%)$ \\
$10.1-18$ & 679 & $59(8.7 \%)$ & $138(20.3 \%)$ & $482(71.0 \%)$ \\
$18+$ & 125 & $8(6.4 \%)$ & $25(20 \%)$ & $92(73.6 \%)$ \\
Total & 3016 & $178(5.9 \%)$ & $576(19 \%)$ & $2262(75 \%)$ \\
\hline
\end{tabular}

TABLE 8: Diagnostic yield by age in speech/language deficits (427 females and 1080 males, total $n=1507)$.

\begin{tabular}{lcccc}
\hline Age buckets & Total tests & $\begin{array}{c}\text { Pathogenic } \\
\text { (\% yield) }\end{array}$ & $\begin{array}{c}\text { VOUS } \\
\text { (\% yield) }\end{array}$ & Normal (\%) \\
\hline 0-3.4 years & 449 & $30(6.7 \%)$ & $100(22.2 \%)$ & $319(71.0 \%)$ \\
$3.5-5.4$ years & 331 & $27(8.2 \%)$ & $63(19.0 \%)$ & $241(72.8 \%)$ \\
5.5-10.4 years & 420 & $52(12.4 \%)$ & $89(21.2 \%)$ & $279(66.4 \%)$ \\
$10.5-18$ & 260 & $28(10.8 \%)$ & $50(19.2 \%)$ & $182(70.0 \%)$ \\
$18+$ & 47 & $9(19.1 \%)$ & $7(14.9 \%)$ & $31(66.0 \%)$ \\
Total & 1507 & $146(9.7 \%)$ & $309(20.5 \%)$ & $1052(69.8 \%)$ \\
\hline
\end{tabular}

Our data demonstrate that diagnostic yield is a complex multivariate function dependent upon several clinical variables including the patient's clinical diagnosis/presentation, age at testing, and referring physician specialty training. An unselected consecutive referral base, with a substantial nonspecialty physician referral component, lack of bias toward selected subgroups (e.g., exclusion of research enriched population of WHS/4p-cohort in the present series) [41], and the active offering of testing to the most recent clinical indication for CMA, ASD, which has an expectably lower rate of such findings [13-15], would be expected to result in a lower overall diagnostic yield in the present series. However, the overall detection rate for clinically established pathogenic CNVs of $9.2 \%$ is equivalent or higher than other reported series/platforms [7-17] despite the inherent bias toward lower rates based on the unselected referral base and focus on ASD. An internal comparison to cases run on the standard array (CytoScan HD) which was the baseline for development of 
TABLE 9: Diagnostic yield by age in neurodevelopmental disorders and/or MCA, excluding ASD (females = 909; males $=1486$; total $n=2395$ )

\begin{tabular}{|c|c|c|c|c|}
\hline Age in years & $\begin{array}{c}\text { Total } \\
\text { (excluding ASD) }\end{array}$ & $\begin{array}{l}\text { Pathogenic } \\
\text { (\% yield) }\end{array}$ & $\begin{array}{c}\text { VOUS } \\
\text { (\% yield) }\end{array}$ & Normal (\%) \\
\hline $0-1$ & 204 & $38(18.6 \%)$ & $37(18.1 \%)$ & $129(63.2 \%)$ \\
\hline $1-3.4$ & 699 & $84(12.0 \%)$ & $146(20.9 \%)$ & $469(67.1 \%)$ \\
\hline $3.5-5.4$ & 344 & $43(12.5 \%)$ & $63(18.3 \%)$ & $238(69.2 \%)$ \\
\hline $5.5-10$ & 589 & $82(13.9 \%)$ & $121(20.5 \%)$ & $386(65.5 \%)$ \\
\hline $10.1-18$ & 461 & 55 (11.9\%) & $83(18.0 \%)$ & $323(70.1 \%)$ \\
\hline $18+$ & 98 & $19(19.4 \%)$ & $15(15.3 \%)$ & $64(65.3 \%)$ \\
\hline Total & 2395 & $321(13.4 \%)$ & 465 (19.4\%) & $1609(67.2 \%)$ \\
\hline
\end{tabular}

TABLE 10: Comparison of FSDX $(N=5487)$ to CytoScan HD $(N=$ 1194 ) arrays performed on same ascertainment base and interpretation paradigm.

\begin{tabular}{lccc}
\hline Array & Pathogenic yield & VOUS yield & Normal \\
\hline $\begin{array}{l}\text { FSDX PLUS } \\
(N=5487)\end{array}$ & $9.2 \%$ & $20.2 \%$ & $70.6 \%$ \\
$\begin{array}{l}\text { CytoScan HD } \\
(N=1172)\end{array}$ & $9.0 \%$ & $14.2 \%$ & $76.7 \%$ \\
\hline
\end{tabular}

the FSDX PLUS array showed a slight, but not significant, increase in detection rate for pathogenic variants from $9.0 \%$ to $9.2 \%$ over the same referral base and underlying patient demographics, using the same interpretation paradigm. The same comparative analysis showed a highly significant differential in detection of VOUS from $14.2 \%$ to $20.2 \%$ (Chisquared $p$ value $<0.0001$ ). The analytical sensitivity of the FSDX PLUS array was recently calculated to be at least $2.6 \%$ greater than the baseline array, which is generally consistent with the observed increase in the overall rate of reportable CNVs (pathogenic plus VOUS) [19].

When individuals with ASD are excluded so as to more closely match populations reported for other CMA platforms/series, the diagnostic yield is further differentiated with diagnostic yields of $13.4 \%$ pathogenic and $19.4 \%$ VOUS and a total detection rate for potentially causative variants, of nearly $33 \%$. It is likely that, even after this correction, other enrichment biases remain in comparing other series to this one.

While significantly lower than the overall population or the ASD-excluded subpopulation $(p<0.0001)$, the diagnostic yield in ASD cases of $5.9 \%$ pathogenic and $19.0 \%$ VOUS exceeds those previously reported [13-15] and supports the value of incremental targeted content for areas of clinical relevance in this important setting for CMA.

The variations in diagnostic yield evident in subgroup analyses may in turn contain clues for future research and causation. For example, the rise in rate of detected abnormalities in the ASD population with age suggests that earlier use of CMA and perhaps other genetic testing may be important. It is estimated that at least $20 \%$ of ASD individuals have an underlying genetic syndrome, but a survey of a large autism center showed that less than $10 \%$ of their population had received any form of genetic evaluation $[42,43]$.
Not surprisingly, patients who are tested in their first year of life for most "indication" groups have the highest diagnostic yield. This is likely due to the probability that increased severity of features would prompt physician investigation earlier in life. It is, however, remarkable that adults ( $>18$ years old) tested also have such a high pathogenic CNV rate observed. This could be due to the relatively small size of this cohort. Alternatively, it may be more reflective of severity in that particular age group. For example, clinicians/families might believe that testing is not as valuable for adults but perform it anyway when the individual is considered to be relatively severely impaired.

In addition to clinically well-defined pathogenic CNVs, a variety of CNVs of less obvious correlation with causation are routinely found on all CMAs. Efforts to better identify and biologically define the relevance of VOUS in these disorders have critical importance to understanding disease mechanisms and, ultimately, give insight to appropriate medical management in the future. An increased rate of CNVs classified as VOUS is therefore of potential clinical importance. Furthermore, VOUS results have been clearly demonstrated to be of great importance to parents of patients with DD/ID/ASD [44-47].

While earlier literature did not typically consider VOUS in the diagnostic yield, this was due to inconsistent criteria for reporting, lack of established databases of normal population variants, and limited sharing of data $[12,13]$. Today with these tools better established, it is common and reasonable to consider VOUS in an overall diagnostic yield $[9,32]$ as many of these variants will evolve into clearly pathogenic finding based on emerging clinical experience and represent an exciting and abundant opportunity to better understand the full range of genomic abnormalities contributing to the neurodevelopmental phenotypes.

Numerous studies have now demonstrated the clinical actionability and utility of CMA testing [32-40]. The increased yield of an optimized array as described here will extend the range and scope of this utility, and it is readily demonstrated through relevant case studies and series to date [35-40]. Of critical importance is the ongoing evaluation of novel methods to assess the potential role of VOUS findings in the underlying pathology of individual patients to realize the maximum benefit of the increased detection rate achieved through array and interpretation optimization. 


\section{Competing Interests}

All authors are employees of Lineagen, Inc., which is a clinical reference laboratory performing genetic testing for individuals with neurodevelopmental disorders.

\section{Acknowledgments}

The authors wish to thank the remarkable patients, families, and providers who participated in this work, Suresh Venkatasubramanian for developing custom code to aid in data analysis, Sean Dixon and Kenny Lentz for database management and technical support, and the entire Lineagen team for their advocacy and dedication to those with neurodevelopmental disorders.

\section{References}

[1] C. A. Boyle, S. Boulet, L. A. Schieve et al., "Trends in the prevalence of developmental disabilities in US children, 1997-2008," Pediatrics, vol. 127, no. 6, pp. 1034-1042, 2011.

[2] M. Manning and L. Hudgins, "Array-based technology and recommendations for utilization in medical genetics practice for detection of chromosomal abnormalities," Genetics in Medicine, vol. 12, no. 11, pp. 742-745, 2010.

[3] G. B. Schaefer and N. J. Mendelsohn, "Clinical genetics evaluation in identifying the etiology of autism spectrum disorders: 2013 guideline revisions," Genetics in Medicine, vol. 15, no. 5, pp. 399-407, 2013.

[4] F. Volkmar, M. Siegel, M. Woodbury-Smith, B. King, J. McCracken, and M. State, "Practice parameter for the assessment and treatment of children and adolescents with autism spectrum disorder," Journal of the American Academy of Child and Adolescent Psychiatry, vol. 53, no. 2, pp. 237-257, 2014.

[5] J. B. Moeschler, M. Shevell, R. A. Saul et al., "Comprehensive evaluation of the child with intellectual disability or global developmental delays," Pediatrics, vol. 134, no. 3, pp. e903-e918, 2014.

[6] D. J. Michelson, M. I. Shevell, E. H. Sherr, J. B. Moeschler, A. L. Gropman, and S. Ashwal, "Evidence Report: genetic and metabolic testing on children with global developmental delay: report of the quality standards Subcommittee of the American Academy of Neurology and the Practice Committee of the Child Neurology Society," Neurology, vol. 77, no. 17, pp. 1629-1635, 2011.

[7] K. M. Heil and C. P. Schaaf, "The genetics of autism spectrum disorders-a guide for clinicians," Current Psychiatry Reports, vol. 15, no. 1, article 334, 2013.

[8] L. Bernardini, V. Alesi, S. Loddo et al., "High-resolution SNP arrays in mental retardation diagnostics: how much do we gain," European Journal of Human Genetics, vol. 18, no. 2, pp. 178-185, 2010.

[9] S. G. McGrew, B. R. Peters, J. A. Crittendon, and J. VeenstraVanderWeele, "Diagnostic yield of chromosomal microarray analysis in an autism primary care practice: which guidelines to implement?" Journal of Autism and Developmental Disorders, vol. 42, no. 8, pp. 1582-1591, 2012.

[10] K. B. Howell, A. J. Kornberg, A. S. Harvey et al., "High resolution chromosomal microarray in undiagnosed neurological disorders," Journal of Paediatrics and Child Health, vol. 49, no. 9, pp. 716-724, 2013.
[11] A. Battaglia, V. Doccini, L. Bernardini et al., "Confirmation of chromosomal microarray as a first-tier clinical diagnostic test for individuals with developmental delay, intellectual disability, autism spectrum disorders and dysmorphic features," European Journal of Paediatric Neurology, vol. 17, no. 6, pp. 589-599, 2013.

[12] D. T. Miller, M. P. Adam, S. Aradhya et al., "Consensus statement: chromosomal microarray is a first-tier clinical diagnostic test for individuals with developmental disabilities or congenital anomalies," American Journal of Human Genetics, vol. 86, no. 5, pp. 749-764, 2010.

[13] Y. Shen, K. A. Dies, I. A. Holm et al., "Clinical genetic testing for patients with autism spectrum disorders," Pediatrics, vol. 125, no. 4, pp. e727-e735, 2010.

[14] L. Edelmann and K. Hirschhorn, "Clinical utility of array CGH for the detection of chromosomal imbalances associated with mental retardation and multiple congenital anomalies," Annals of the New York Academy of Sciences, vol. 1151, pp. 157-166, 2009.

[15] A. L. Beaudet, "The utility of chromosomal microarray analysis in developmental and behavioral pediatrics," Child Development, vol. 84, no. 1, pp. 121-132, 2013.

[16] H. Mason-Suares, W. Kim, L. Grimmett et al., "Density matters: comparison of array platforms for detection of copy-number variation and copy-neutral abnormalities," Genetics in Medicine, vol. 15, no. 9, pp. 706-712, 2013.

[17] R. Pfundt, K. Kwiatkowski, A. Roter et al., "Clinical performance of the CytoScan Dx Assay in diagnosing developmental delay/intellectual disability," Genetics in Medicine, vol. 18, no. 2, pp. 168-173, 2016.

[18] H. M. Kearney, S. T. South, D. J. Wolff, A. Lamb, A. Hamosh, and K. W. Rao, "American College of Medical Genetics recommendations for the design and performance expectations for clinical genomic copy number microarrays intended for use in the postnatal setting for detection of constitutional abnormalities," Genetics in Medicine, vol. 13, no. 7, pp. 676-679, 2011.

[19] C. H. Hensel, R. Vanzo, M. Martin et al., "Analytical and clinical validity study of FirstStep ${ }^{\text {Dx }}$ PLUS: a chromosomal microarray optimized for patients with neurodevelopmental conditions," PLoS Currents, 2016.

[20] N. Matsunami, D. Hadley, C. H. Hensel et al., "Identification of rare recurrent copy number variants in high-risk autism families and their prevalence in a large ASD population," PLoS ONE, vol. 8, no. 1, Article ID e52239, 2013.

[21] J. Sebat, B. Lakshmi, D. Malhotra et al., "Strong association of de novo copy number mutations with autism," Science, vol. 316, no. 5823, pp. 445-449, 2007.

[22] C. R. Marshall, A. Noor, J. B. Vincent et al., "Structural variation of chromosomes in autism spectrum disorder," American Journal of Human Genetics, vol. 82, no. 2, pp. 477-488, 2008.

[23] S. L. Christian, C. W. Brune, J. Sudi et al., "Novel submicroscopic chromosomal abnormalities detected in autism spectrum disorder," Biological Psychiatry, vol. 63, no. 12, pp. 1111-1117, 2008.

[24] J. T. Glessner, K. Wang, G. Cai et al., "Autism genome-wide copy number variation reveals ubiquitin and neuronal genes," Nature, vol. 459, no. 7246, pp. 569-573, 2009.

[25] M. Bucan, B. S. Abrahams, K. Wang et al., "Genome-wide analyses of exonic copy number variants in a family-based study point to novel autism susceptibility genes," PLoS Genetics, vol. 5, no. 6, Article ID e1000536, 2009.

[26] D. Pinto, A. T. Pagnamenta, L. Klei et al., "Functional impact of global rare copy number variation in autism spectrum disorders," Nature, vol. 466, no. 7304, pp. 368-372, 2010. 
[27] P. Szatmari, A. D. Paterson, L. Zwaigenbaum et al., "Mapping autism risk loci using genetic linkage and chromosomal rearrangements," Nature Genetics, vol. 39, no. 3, pp. 319-328, 2007.

[28] L. A. Weiss, Y. Shen, J. M. Korn et al., "Association between microdeletion and microduplication at 16p11.2 and autism," New England Journal of Medicine, vol. 358, no. 7, pp. 667-675, 2008.

[29] M.-L. Jacquemont, D. Sanlaville, R. Redon et al., "Array-based comparative genomic hybridisation identifies high frequency of cryptic chromosomal rearrangements in patients with syndromic autism spectrum disorders," Journal of Medical Genetics, vol. 43, no. 11, pp. 843-849, 2006.

[30] S. T. South, C. Lee, A. N. Lamb, A. W. Higgins, and H. M. Kearney, "ACMG Standards and Guidelines for constitutional cytogenomic microarray analysis, including postnatal and prenatal applications: revision 2013," Genetics in Medicine, vol. 15, no. 11, pp. 901-909, 2013.

[31] J. R. MacDonald, R. Ziman, R. K. C. Yuen, L. Feuk, and S. W. Scherer, "The database of genomic variants: a curated collection of structural variation in the human genome," Nucleic Acids Research, vol. 42, no. 1, pp. D986-D992, 2014.

[32] J. L. Roberts, K. Hovanes, M. Dasouki, A. M. Manzardo, and M. G. Butler, "Chromosomal microarray analysis of consecutive individuals with autism spectrum disorders or learning disability presenting for genetic services," Gene, vol. 535, no. 1, pp. 70$78,2014$.

[33] J. Saam, J. Gudgeon, E. Aston, and A. R. Brothman, "How physicians use array comparative genomic hybridization results to guide patient management in children with developmental delay," Genetics in Medicine, vol. 10, no. 3, pp. 181-186, 2008.

[34] M. E. Coulter, D. T. Miller, D. J. Harris et al., "Chromosomal microarray testing influences medical management," Genetics in Medicine, vol. 13, no. 9, pp. 770-776, 2011.

[35] J. W. Ellison, J. B. Ravnan, J. A. Rosenfeld et al., "Clinical utility of chromosomal microarray analysis," Pediatrics, vol. 130, no. 5, pp. e1085-e1095, 2012.

[36] E. R. Riggs, K. E. Wain, D. Riethmaier et al., "Chromosomal microarray impacts clinical management," Clinical Genetics, vol. 85, no. 2, pp. 147-153, 2014.

[37] L. B. Henderson, C. D. Applegate, E. Wohler, M. B. Sheridan, J. Hoover-Fong, and D. A. S. Batista, "The impact of chromosomal microarray on clinical management: a retrospective analysis," Genetics in Medicine, vol. 16, no. 9, pp. 657-664, 2014.

[38] V. Q. Tao, K. Y. K. Chan, V. W. Y. Chu et al., "The clinical impact of chromosomal microarray on paediatric care in Hong Kong," PLoS ONE, vol. 9, no. 10, Article ID e109629, 2014.

[39] M. R. Sdano, R. J. Vanzo, M. M. Martin et al., "Clinical utility of chromosomal microarray analysis of dna from buccal cells: detection of mosaicism in three patients," Journal of Genetic Counseling, vol. 23, no. 6, pp. 922-927, 2014.

[40] M. M. Martin, R. J. Vanzo, M. R. Sdano, A. L. Baxter, and S. T. South, "Mosaic deletion of 20pter due to rescue by somatic recombination," American Journal of Medical Genetics Part A, vol. 170, no. 1, pp. 243-248, 2016.

[41] K. S. Ho, S. T. South, A. Lortz et al., "Chromosomal microarray testing identifies a $4 \mathrm{p}$ terminal region associated with seizures in Wolf-Hirschhorn syndrome," Journal of Medical Genetics, vol. 53, no. 4, pp. 256-263, 2016.

[42] F. Gurrieri, "Working up autism: the practical role of medical genetics," American Journal of Medical Genetics Part C: Seminars in Medical Genetics, vol. 160, no. 2, pp. 104-110, 2012.
[43] T. L. Wenger, C. Kao, D. M. McDonald-McGinn et al., “The role of mGluR copy number variation in genetic and environmental forms of syndromic autism spectrum disorder," Scientific Reports, vol. 6, article 19372, 2016.

[44] M. Reiff, B. A. Bernhardt, S. Mulchandani et al., "'What does it mean?': uncertainties in understanding results of chromosomal microarray testing," Genetics in Medicine, vol. 14, no. 2, pp. 250 258, 2012.

[45] M. Reiff, E. Giarelli, B. A. Bernhardt et al., "Parents' perceptions of the usefulness of chromosomal microarray analysis for children with autism spectrum disorders," Journal of Autism and Developmental Disorders, vol. 45, no. 10, pp. 3262-3275, 2015.

[46] S. Jez, M. Martin, S. South, R. Vanzo, and E. Rothwell, "Variants of unknown significance on chromosomal microarray analysis: parental perspectives," Journal of Community Genetics, vol. 6, no. 4, pp. 343-349, 2015.

[47] E. J. Wilkins, A. D. Archibald, M. A. Sahhar, and S. M. White, “'It wasn't a disaster or anything': Parents' experiences of their child's uncertain chromosomal microarray result," American Journal of Medical Genetics Part A, vol. 170, no. 11, pp. 28952904, 2016. 

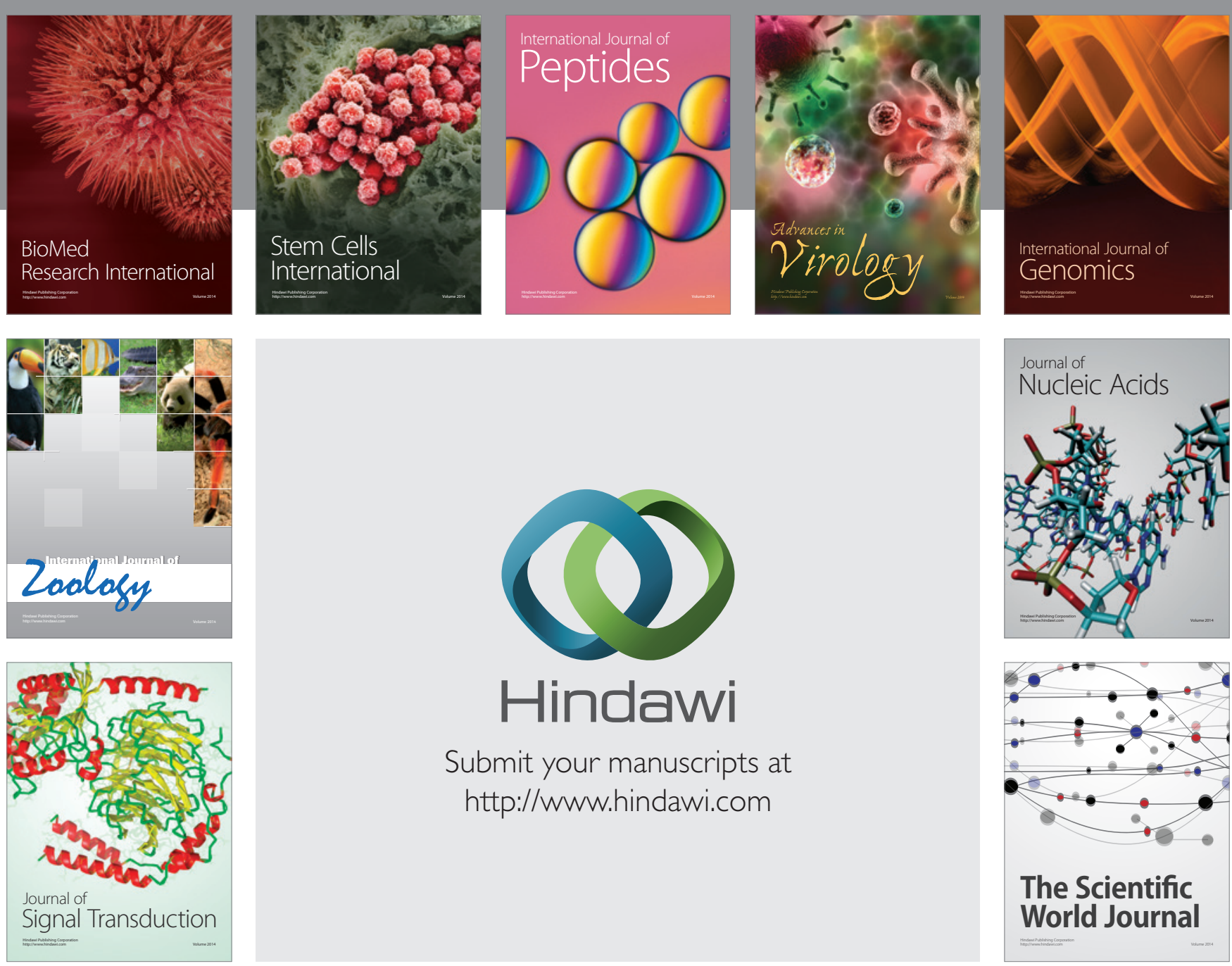

Submit your manuscripts at

http://www.hindawi.com
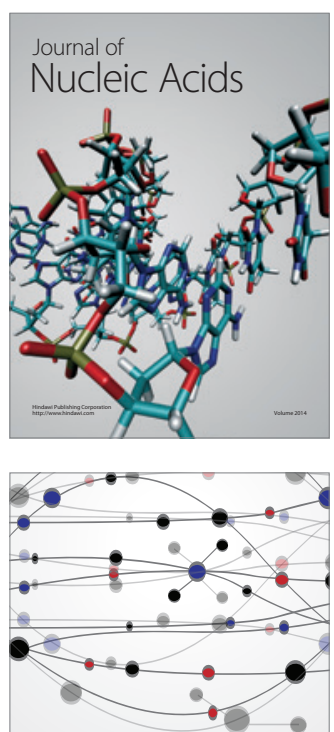

The Scientific World Journal
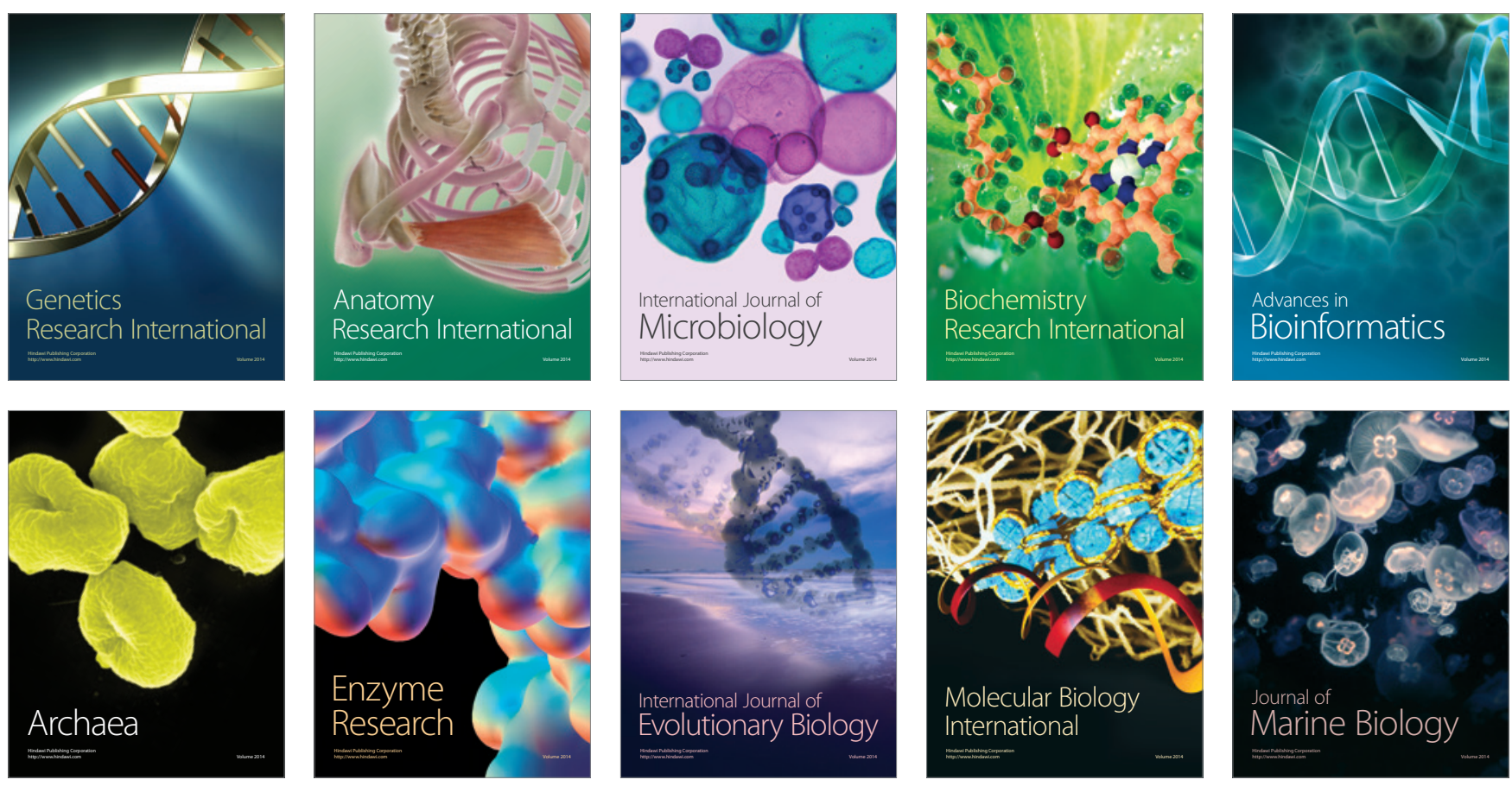